\title{
A mediação da informação no âmbito da arquivística
}

\author{
Letícia Elaine Ferreira
}

\begin{abstract}
Mestranda do Programa de Pós-Graduação em Ciência da Informação da Universidade Estadual Paulista Júlio de Mesquita Filho (UNESP)
\end{abstract}

Oswaldo Francisco de Almeida Júnior

Professor Doutor do Programa de Pós-Graduação em Ciência da Informação da Universidade Estadual Paulista Júlio de Mesquita Filho (UNESP)

O texto analisa a Arquivologia e sua relação com a mediação da informação. Defende que a base teórica da Arquivologia proporciona condições fundamentais para que, no âmbito da prática, se desenvolvam operações metodológicas que resultem no tratamento adequado dos documentos. Dessa forma, ressaltando a práxis arquivística, compreende-se a utilização de instrumentos e técnicas como uma mediação de sistemas, na qual as etapas da metodologia arquivística atendem ao objetivo primordial de organização de massas documentais, possibilitando seu tratamento, com o propósito de recuperar e disponibilizar as informações dos respectivos conjuntos documentais. A atuação técnica de profissionais da informação, especificamente do arquivista, nesse contexto, já configura uma mediação, mas uma mediação, sobretudo, que lida com a protoinformação. Dessa forma, argumenta-se que é necessário entender como essa protoinformação torna-se informação. Afirmase que, nesse sentido, a mediação da informação apresenta-se como objeto que vislumbra tal compreensão, partindo, para tanto, do parâmetro da apropriação da informação dos usuários-pesquisadores do arquivo e sua produção e/ou alteração do conhecimento resultante da relação com esse ambiente, para garantir, de fato, uma mediação da informação arquivística. Advoga que essa perspectiva inovadora da mediação da informação nos arquivos, caracteriza uma abordagem que carece de maiores reflexões na área.

Palavras-chaves: Arquivologia; arquivística; Mediação da informação. 


\section{Mediation of information within the archive}

The text analyzes the Archivology and its relationship with the mediation of information. Argues that the theoretical basis of Archival Science provides key condition of the scope of practice, to develop methodological operations that result in the proper handling of documents. Thus, highlighting the archival practice includes the use of tools and techniques what is one system mediation, where the stages of the methodology archival has the primordial objective with organization archival, to retrieve and available information from respective sets of documents. The technical work of information professionals, specifically the archivist in this context already set up a mediation, but, especially dealing with the protoinformation. It should be recognized as it becomes protoinformation in information. Thus, it is argued that it is necessary to understand how this proto-information becomes information. It is said that in this sense, the mediation of information presents itself as an object that sees such an understanding, of the beginning to end, the parameter of the appropriation of information of usersresearchers of archives, and their production and / or modification of knowledge resulting from the relationship with this environment to ensure in fact a mediation of archival information. Hopes that this innovative approach of mediation of information in the archives featuring an approach that requires one further reflection in the area.

Keywords: Archival; Archival organization; Mediation of information.

Recebido em 26.04.2011 Aceito em 08.02.2013

\section{Introdução}

$\mathrm{Na}$ concepção da Ciência da Informação, como uma área investigativa das propriedades e procedimentos da informação, bem como da busca de controle de fluxos informacionais, meios, técnicas e métodos para que os processos organizacionais tornem a informação acessível e, também, para que haja êxito na recuperação, armazenamento e transmissão da informação, compreende-se que uma das suas funções primordiais é a de auxiliar a melhoria das instituições, no que tange aos 
processamentos de cunho informacional, visando à acumulação e transmissão do conhecimento.

A Ciência que traz a informação como escopo de trabalho, caracteriza-se, também, pela efetividade prática, que possibilita o desenvolvimento de produtos e serviços. Dessa maneira, compactua-se com Borko (1968), no sentido em que adverte ele ser a teoria e a prática, no âmbito da Ciência da Informação, uma relação "inexorável".

Diante da relação teoria/prática, torna-se interessante ressaltar essa conexão através de uma abordagem incipiente na reflexão do objeto da Ciência da Informação: a mediação da informação. Pensá-la, enquanto objeto de estudo da Ciência da Informação, implica em compreender que a informação só atinge êxito quando é apropriada pelos sujeitos e esse processo deve, inevitavelmente, resultar na alteração/modificação do conhecimento prévio dos mesmos (ALMEIDA JúNIOR, 2008, p. 46).

O enfoque nos usuários dos equipamentos informacionais (arquivos, bibliotecas, museus e centros de documentação), dimensiona a mediação da informação, de forma a contemplar todo o escopo do processo informacional - desde o suporte onde a informação está registrada até a sua relação com os usuários, passando pelos procedimentos técnicos dos profissionais da informação. Nesse processo, a informação ainda não está "completa", está em fase "embrionária"; por isto, caracterizada como "protoinformação" por anteceder a sua relação e apropriação pelos sujeitos (ALMEIDA JÚNIOR, 2007, p. 34). Dessa maneira, a concepção desse objeto de estudo revela-se inovadora e abrangente, já que concebe a interação entre suportes, sujeitos e conhecimento, como integrantes desse universo informacional.

\section{0 processo mediador da informação}

É interessante ressaltar a mediação da informação, revisitando o conceito de informação enunciado por Buckland (1991), que estabelece sua distinção em três "níveis". A informação-como-coisa atribuída aos objetos é materializada e, portanto, possui a qualidade de conhecimento comunicado, algo que informa, podendo ser materializada, por exemplo, nos documentos. A informação-como-processo é circunstancial, ou seja, depende da circunstância e relevância para modificar um conhecimento mediante aquilo que é informado, o ato de informar gera uma mudança no conhecimento já existente. Consequentemente, a informação-comoconhecimento acontece mediante a absorção da informação-como-coisa e da informação-como-processo, o que equivale compreender o resultado na modificação/alteração do conhecimento de algum indivíduo, após seu contato com um suporte informacional.

Nesse viés, é interessante refletir que o processo informação-comocoisa, informação-como-processo e informação-como-conhecimento requer, substancialmente, interferências: seja por instrumentos materiais, seja por processos cognitivos e/ou "mentais" capazes de subsidiar a interação da totalidade da informação nesse ciclo e garantir sentido, significado a ela. Ora, a partir da leitura de um documento, é possível que 
as informações geradas, nesse momento, associem-se às informações que o indivíduo já possui, constituindo um "processo" no qual a alteração/modificação de seu conhecimento dá-se acrescentando ou questionando um conhecimento prévio.

Dessa maneira, Marco Antônio de Almeida (2007, p. 9) elucida que tal processo da informação, em Buclankd (1991), é

[...] uma distinção heurística; ele sabe que, concretamente, a 'informação como coisa' se constitui a partir de relações e interações com os movimentos da 'informação como processo' e da 'informação como conhecimento'. Se os sistemas de informação atuam como mediadores materiais, a sua constituição (a partir da passagem de tangíveis para intangíveis e vice-versa, na terminologia de Buckland) aponta para uma mediação humana, que muitas vezes é esquecida na discussão sobre as novas tecnologias de informação e comunicação.

Nessa constatação, destacam-se observações importantes relacionadas à questão dos mediadores materiais (sistemas de informação) e de suas técnicas e ferramentas que, inevitavelmente, se atrelam à mediação humana. Como bem se evidencia, o processo informacional, quer seja no âmbito dos procedimentos técnicos ou na construção e/ou alteração de um conhecimento, encontra-se mediado.

Ressalta-se que a informação, visando o conhecimento, ainda não se encontra assimilada, processada. Por isso, Almeida Júnior (2007, p. 34) acredita que essa informação, caracterizada por não estar ainda apropriada pelo indivíduo, por estar sendo "trabalhada" no âmbito das técnicas das Ciências da Informação, (processadas, organizadas e armazenadas) e, por consequência, não se apresentar ainda de forma "latente", não pode ser caracterizada como uma informação "de fato". É, antes, uma protoinformação.

A consumação da protoinformação em informação só é possível se a relação do indivíduo com o suporte documental fornecer-lhe subsídios capazes de "apropriar" a informação. Dito de outro modo, só é possível transformar a protoinformação em informação no âmbito do universo cognoscível, quando, na relação usuário-suporte, modifica-se, altera-se um conhecimento já adquirido. Presume-se, assim, que o conhecimento pode ser entendido como o principal resultado da mediação da informação.

\section{Mediando a informação arquivística: das técnicas documentais à apropriação da informação nos arquivo}

Os profissionais da informação, no tocante ao público a quem destina servir, devem pressupor que suas ações mediarão o conhecimento de seus "usuários". É a relação destes últimos com o documento que 
proporcionará a abstração de conteúdos "protoinformados" (conjuntos de elementos sedimentados em suportes informacionais, tratados tecnicamente). Dessa maneira, com o propósito de que tais elementos documentais efetivem-se de fato em informação, torna-se primordial a relação com os sujeitos.

Essa mediação, capaz de resignificar, suplementar ou modificar o conhecimento anterior dos usuários, transformando-a em informação condição primordial para a mediação da informação - só é possível se, no contato com os suportes documentais, houver absorção e interpretação da "protoinformação" (encontrada nos mais variados suportes), por parte desses usuários.

Almeida Júnior (2009, p. 34) defende que a mediação da informação perpassa todos os serviços relacionados às práticas dos profissionais da informação. No entanto, em algumas dessas ações, a mediação se apresenta de maneira implícita sem, necessariamente, a presença concreta do usuário, ainda que se perceba certa preocupação com ele.

É, nesse contexto, que, no âmbito do procedimento arquivístico, a organização documental arquivística pode apresentar-se como uma ferramenta que prepara a "protoinformação" no âmbito da técnica, visando a sua transformação em uma "informação" no âmbito da relação profissional arquivista - usuário, de onde é possível constatar a progressão: documento (suporte) - organização documental pesquisador/usuário - apropriação da informação produção/modificação/alteração de conhecimento.

Não obstante as etapas da organização documental arquivística, tais como identificação, classificação, ordenação e descrição documental lidarem nesse contexto, com "protoinformações" - que estão sendo processadas pelas metodologias arquivísticas e que poderão (ou não) resultar em informação - na medida em que se aproxima o final de todo este processo, busca-se possibilitar que a apropriação das informações dos documentos tecnicamente trabalhados, sejam o resultado da interação desses documentos com os respectivos usuários e/ou pesquisadores.

As etapas do processamento técnico de documentos de arquivo assumem destaques nas tarefas organizacionais, especialmente em tarefas em que a eleição de métodos e metodologias a serem desenvolvidas (como a identificação, classificação e descrição arquivística) implica, posteriormente, no resultado satisfatório da utilização da informação.

Constata-se em Antonia Heredia Herrera (1991, p. 253), que, na etapa da classificação arquivística, o arquivista deve imprescindir de um ornamento teórico-metodológico capaz de visualizar estratégias e soluções eficazes para a organização de massas documentais.

Por isso, identificar os níveis nos quais se estabelecem a classificação (série, subgrupo, grupo e fundo de arquivo) e hierarquizálos, bem como produzir instrumentos que refletem essa lógica orgânica dos arquivos, coloca o profissional arquivista em contato com conteúdos "protoinformativos" dos documentos, que são tratados com o objetivo de 
atendimento da instituição em que se encontram e, uma vez disponibilizados para o acesso (foco secundário da organização arquivística), serão interpretados futuramente pelos usuários.

Dessa forma, embora haja uma mediação entre o veículo documento, a informação nele existente e o processamento técnico efetivado pelo arquivista, essa mediação não visa diretamente (nessa etapa) o enfoque no usuário. Trabalha-se, nesse contexto, a utilização dessa "informação-ainda-não-latente" no âmbito da identificação, seleção, classificação e processamento informacional, o que a caracteriza, portanto, como uma mediação implícita.

Por sua vez, a mediação explícita, segundo Almeida Júnior (2009, p. 93), formaliza-se em dois momentos: um implícito, em que se apresentam as ações conscientes, realizadas com base em conhecimentos nos quais há domínios e tem-se um "controle razoável"; e um explícito, no qual as ações transparecem de forma inconsciente e não controláveis (não assentadas em técnicas), chocando-se com o conhecimento consciente. Para que haja a mediação explícita, é imprescindível a presença do usuário dos espaços informacionais.

A mediação explícita, por seu lado, ocorre nos espaços em que a presença do usuário é inevitável, é condição sine qua non para sua existência, mesmo que tal presença não seja física, como, por exemplo, nos acessos a distância em que não é solicitada a interferência concreta e presencial do profissional da informação (ALMEIDA JúNIOR, 2009, p. 92-93).

Nesse contexto, é importante refletir sobre os usuários dos arquivos, já que o acesso à informação, em seu âmbito, é a etapa final de toda a função arquivística. Barros e Neves (2009, p. 55) concordam que a função do arquivo, no que tange ao acesso à informação, é tornar público e disponíveis as informações que se encontram em seus conjuntos documentais, visto que, na concepção dos autores, o arquivo é, também, produtor de conhecimento.

Essas constatações, embora passíveis de serem observadas em todo universo arquivístico, podem ser evidentemente exemplificadas no âmbito do arquivo permanente. Parafraseando Bellotto (2004, p. 116), é nele que os documentos passam da condição de "arsenal da administração" para a de "celeiro da história" - atendendo à sistematização da Teoria das Três Idades.

Dessa forma, é lícito afirmar que o arquivo carrega uma função social de aplicabilidade prática: garantir que a informação (protoinformação) contida em seus conjuntos documentais possa contribuir para a sociedade. Embora as idades documentais (arquivo corrente, intermediário e permanente) sejam tratadas, nessa perspectiva da mediação informacional, sem relativizações, há de se considerar que é na terceira idade documental, ou seja, nos arquivos permanentes, que se 
tem maior evidência da "informação latente" com vistas ao conhecimento e, também, à memória.

Nessa interface arquivística, torna-se relevante a afirmação de Terry Cook (1998, p. 144), que salienta que os arquivistas passaram por uma mudança, no tocante à custódia: saíram da passividade com que custodiavam os "resíduos" documentais, ativos conformadores da herança arquivística; e, agora, intervém e deliberam nos padrões de arquivamento. Com essa transformação, verificada ao longo do tempo, o autor afirma que os arquivistas tornaram-se "construtores muito ativos da memória social" (COOK, 1998, p. 144).

A conformidade salientada por terry Cook (1998, p. 144), diante de "resíduos" documentais, pode ser entendida como a posição na qual os arquivistas se colocavam como guardadores de "protoinformações" e, posteriormente, com o ativo das relações de fato estabelecidas com os documentos, passaram a ser caracterizados como construtores da memória - os conhecimentos advindos da apropriação da informação pela leitura e procedimentos arquivísticos possibilitou a análise e interpretação documental e instigou, sem dúvida, ativos da informação latente das massas documentais.

Outra concepção de relevância, nesse sentido, é a definição da Arquivística pós-custodial por Brito (2005, p. 32):

[...] uma das disciplinas que atuam e se propõe a preservar e organizar intelectualmente a informação arquivística contida em um arquivo, a disponibilizá-la de modo rápido e seguro, e a garantir o acesso do usuário, para que efetivamente esta informação venha gerar conhecimento.

É importante, ainda, atentar para a constatação já anunciada por Bellotto (1996, p. 8), ao afirmar que os arquivos públicos funcionam como conjuntos de registros válidos da legislação de base e funcionamento do governo, dos direitos e deveres do cidadão para com o Estado e, reciprocamente, do Estado para com o cidadão, e, ainda, quando tece considerações sobre os arquivos privados (empresariais ou institucionais), que fixam as provas de existência legal e do andamento (atividades-meio e atividades-fins) dessas entidades, assim como suas relações com 0 governo e com seus diferentes públicos. Dessa forma, o arquivo é o reflexo da sociedade na qual se insere e, portanto, não funciona alheio a ela - observação que já prevê uma mediação, sobretudo, humana.

É, nesse sentido, que é válido, no tocante às instituições arquivísticas, atentar-se aos procedimentos técnicos e atendimento dos usuários dos arquivos. Ora, para que o arquivo possa cumprir sua função social e garantir o direito dos cidadãos, há de se pensar não somente na relação do pesquisador-usuário do arquivo, como, também, nos procedimentos adotados para que os documentos possam ser 
encontrados, recuperados, consultados e, dessa forma, possibilitar o êxito do usuário e garantir efetiva mediação da informação arquivística.

Caso a relação dos arquivistas caracterizar-se por ser de maneira direta com o público, essa situação os coloca como mediadores explícitos da informação. Pode-se, aqui, sim, utilizar a palavra informação com a pretensão de lhe dar caráter latente, já que, pressupostamente, através da relação do indivíduo com o documento, seu percurso cognitivo será alterado. Através da leitura, tão importante nesse contexto de apropriação da informação por parte do usuário acesso, é que aquela (proto) informação pode tornar-se "madura". Como salienta Almeida Júnior (2007, p. 36), "[...] a leitura pode se utilizar de qualquer tipo de documento e seu processo se concretiza no momento em que o usuário se relaciona com o documento".

Nesse processo, enaltece-se a apropriação da informação, no momento em que o indivíduo transforma seu conhecimento de forma a modificá-lo, alterá-lo. Não cabe somente à informação registrada ser objeto da Ciência da Informação: adicione-se a ela as atividades culturais inserida nos ambientes informacionais. Essa associação torna-se, para Almeida Júnior (2007, p.36), o objeto da Ciência da Informação.

A sugestão, em outras palavras, é que a mediação da informação seja pensada como objeto da área, já que ela totaliza todo o processo informacional. Nas palavras de Almeida Júnior (2007, p. 34): "[...] Denomino o processo que vai da comunicação, via documento, até a transformação do conhecimento de uma pessoa, de mediação da informação".

Assim, importa atentar-se para o conceito de mediação da informação enfatizado pelo autor:

[...] toda ação de interferência - realizada pelo profissional da informação -, direta ou indireta; consciente ou inconsciente; singular ou plural; individual ou coletiva; que propicia a apropriação de informação que satisfaça, plena ou parcialmente, uma necessidade informacional (ALMEIDA JÚNIOR, 2009, p. 92).

Uma característica marcante da mediação da informação é a interferência. Não há como negar que o próprio profissional da informação, seja ele arquivista, bibliotecário ou museólogo interfere no tratamento da informação, bem como no atendimento ao usuário. Seus valores, conhecimentos e preceitos não são apagados na relação com o tratamento da informação. Por isso, longe de serem neutros, esses profissionais devem atentar, segundo Almeida Júnior (2007, p.36), para que essa interferência não se confunda com a manipulação, uma vez que seus limites são tênues.

A transformação do conhecimento mediada pela relação do usuário com o suporte é a condição para que exista, de fato, a informação. 
Respalda-se, na mediação, o construto final do processo cognitivo dos indivíduos - o conhecimento.

Tais reflexões possibilitam a defesa de que os arquivos, entre outras funções, produzem conhecimento. Essa afirmação é decisiva, visto que se observa uma nova "postura" dessa instituição. O arquivo não é apenas o braço da administração e guardador de memória: é, também, produtor e disseminador de conhecimento.

\section{Considerações finais}

Diante do caráter técnico vinculado aos arquivistas, importa reconhecer como primária e estigmatizada a acepção de que à atuação do profissional, bem como ao condicionamento dos usuários do arquivo, permanece a mística aparência de que essa relação encerra-se na técnica pela técnica. Revela-se primordial o contato com o suporte documental. Entretanto, somente essa relação não possibilita a real e crescente função do arquivo: mais do que organizar para testemunhar, os arquivos possibilitam, através da mediação, um percurso que pode resultar em conhecimento.

A própria etapa de organização documental é, por si só, uma mediação: de técnica, de sistemas, de ferramentas. No entanto, posterior ao tratamento documental, o enfoque na mediação humana coloca ao arquivo, ao arquivista e aos procedimentos com os quais atua, um desafio: organizar com foco na produção do conhecimento e, em especial, com foco no usuário.

Essas questões revelam-se inovadoras na Arquivologia, razão pela qual não se pretende esgotá-las neste contexto. Portanto, pensar a mediação da informação na Arquivologia implica pensar em reformulações teórico-metodológicas em novos posicionamentos profissionais e em situar a área frente às expectativas assinaladas pela era pós-custodial.

\section{Referências}

ALMEIDA, M. A. de. Mediação cultural e da informação: Considerações socioculturais e políticas em torno de um conceito. In: ENCONTRO NACIONAL DE PESQUISA EM CIÊNCIA DA INFORMAÇÃO, 8., Salvador, 2007. Anais... Salvador: ANCIB, 2007. 16 p.

ALMEIDA JÚNIOR, O. F. Leitura, mediação e apropriação da informação. In: SANTOS, J. P. dos. (Org.). A leitura como prática pedagógica na formação do profissional da informação. Rio de Janeiro: Biblioteca Nacional, 2007. p. 33-45.

ALMEIDA JÚNIOR, O. F. Mediação da informação: ampliando o conceito de disseminação. In: VALENTIM, M. L. P. (Org.). Gestão da informação e do conhecimento no âmbito da Ciência da Informação. São Paulo: Polis: Cultura Acadêmica, 2008. p. 41-54.

ALMEIDA JÚNIOR, O. F. Mediação da informação e múltiplas linguagens. Pesq. bras. Ci. Inf., Brasília, v. 2, n. 1, p. 89-103, jan./dez. 2009. 
BARROS, D. S; NEVES, D. A. de B. Arquivo e memória: uma relação indissociável. Transinformação, Campinas, v. 21, n. 1, p. 55-61, jan./abr. 2009.

BELLOTTO, H. L. A imagem do arquivista na sociedade e o ensino da Arquivologia. Arquivo \& História: revista do arquivo público do Estado do Rio de Janeiro. Rio de Janeiro. Arquivo Público do Estado de Rio de Janeiro, 1996. n. 2, 70 p.

BELLOTTO, H. L. Arquivos permanentes: tratamento documental. 2. ed. Rio de

Janeiro: FGV, 2004. 320p.

BORKO, H. Information science: what is it? American Documentation (pre1986) ABI/INFORM Global, v. 19, n. 1, p. 3-5, jan.1968.

BRITO, D. M de. A informação arquivística na arquivologia pós-custodial. Arquivística.net, Rio de Janeiro, v. 1, n. 1, p. 31-50, jan./jun. 2005.

BUCKLAND, M. K. Information as thing. Journal of the American Society for Information Science (JASIS), v. 5, n. 5, p. 351-360, 1991.

COOK, T. Arquivos pessoais e arquivos institucionais: para um entendimento arquivístico comum da formação da memória em um mundo pós-moderno. Estudos Históricos, Rio de Janeiro, v. 11, n. 21, p. 129-152, 1998.

HEREDIA HERRERA, A. Organización I: classificación de fondos.In: HEREDIA HERRERA, A. Archivística general: teoría y práctica. 5. ed. Sevilla : Diputación Provincial, 1991. p 253-281. 